\title{
Phonological priming in German Sign Language: An eye tracking study using the Visual World Paradigm
}

\author{
Anne Wienholz ${ }^{1,2}$, Derya Nuhbalaoglu ${ }^{1,3}$, Markus Steinbach ${ }^{1}$, Annika Herrmann ${ }^{4}$, and \\ Nivedita Mani ${ }^{1}$ \\ ${ }^{1}$ University of Goettingen, ${ }^{2}$ Boston University, \\ ${ }^{3}$ Goethe University Frankfurt, ${ }^{4}$ University of Hamburg
}

\begin{abstract}
A number of studies provide evidence for a phonological priming effect in the recognition of single signs based on phonological parameters and that the specific phonological parameters modulated in the priming effect can influence the robustness of this effect. This eye tracking study on German Sign Language examined phonological priming effects at the sentence level, while varying the phonological relationship between prime-target sign pairs. We recorded participants' eye movements while presenting videos of sentences containing either related or unrelated prime-target sign pairs, and pictures of the target and an unrelated distractor. We observed a phonological priming effect for sign pairs sharing handshape and movement while differing in location parameter. Taken together, the data suggest a difference in the contribution of sign parameters to sign recognition and that sub-lexical features influence sign language processing.
\end{abstract}

Keywords: German Sign Language, eye tracking, Visual World Paradigm, sentence processing, phonological priming

\section{Introduction}

Studies provide evidence for comparable lexical and sub-lexical organization of linguistic units from spoken and sign languages in the mental lexicon, even if modality-specific differences do not allow for direct comparisons between the two language modalities. Similar to words in spoken language, signs can be decomposed into smaller meaningless phonological units. Stokoe et al. (Stokoe 1960; Stokoe, Casterline \& Croneberg 1965) were the first to describe specific hand configurations as phonemes in sign languages, i.e., in this case for American Sign Language (ASL). ${ }^{1}$ Each configuration can be specified by the major phonological parameters handshape, i.e., selection and flexion of (the) fingers, location, i.e., place of articulation of a sign in relation to the body, and movement, i.e., movements of the whole hand or arm as well

1. Note that Stokoe and colleagues (Stokoe 1960; Stokoe, Casterline \& Croneberg 1965) did use the term chereme to introduce the concept of phonemes. 
as hand-internal movements including changes in handshape and palm orientation (Twilhaar \& van den Bogaerde 2016). ${ }^{2}$

Furthermore, Stokoe and others (Stokoe 1960; Stokoe, Casterline \& Croneberg 1965; Klima \& Bellugi 1979) highlight that parameters are produced simultaneously rather than sequentially. This suggests that single parameters might be processed in a parallel manner as well (Carreiras 2010). However, succeeding studies revealed that parameters unfold over time, raising the possibility of sequential processing of sign language parameters (Liddell 1984; Sandler 1986; Liddell \& Johnson 1989). Indeed, we note that different parameters are available to the processor at different time points even in the transition phase between two signs (Hosemann et al. 2013). The question then arises how the different parameters influence the processing of signs. Here, the high temporal resolution of eye tracking paradigms provide us a privileged window into the recognition of signs as the sign unfolds. As we will show in the following sections, studies investigating different sign languages reveal that sign recognition, indeed, unfolds over time (Emmorey \& Corina 1990) and that phonological parameters vary in their influence on sign recognition and processing.

\subsection{Effects of phonological parameters}

Studies have typically examined the status of sign language phonological parameters in sign recognition by varying the degree of overlap between two signs (see Table 1 for an overview). Summarizing the effects of the parameters investigated in these studies, the data highlight the special status of the location parameter compared to all other parameters. This parameter is acquired and identified first (Siedlecki Jr \& Bonvillian 1993; Morgan, Barrett-Jones \& Stoneham 2007), encoded more robustly in the mental lexicon (Thompson, Emmorey \& Gollan 2005; Orfanidou et al. 2009) and leads to robust inhibition effects in picture-sign interference tasks (Baus et al. 2008; Baus, Gutiérrez \& Carreiras 2014). In contrast, the handshape and movement parameter show a more diverse and less coherent picture.

Table 1. Overview of studies examining effects of phonological parameters

\begin{tabular}{|l|l|l|l|}
\hline \multicolumn{1}{|c|}{ Authors } & Language & \multicolumn{1}{c|}{ Paradigm } & \multicolumn{1}{c|}{ Results } \\
\hline $\begin{array}{l}\text { Morgan, Barrett- } \\
\text { Jones \& Stoneham } \\
(2007)\end{array}$ & BSL & Case study & $\begin{array}{l}\text { Location is produced correctly } \\
\text { first, followed by movement and } \\
\text { handshape. }\end{array}$ \\
\cline { 1 - 2 } $\begin{array}{l}\text { Siedlecki Jr \& } \\
\text { Bonvillian (1993) }\end{array}$ & ASL & Corpus data & \\
\hline
\end{tabular}

2. Some researchers argued for including nonmanuals (Pfau \& Quer 2010) and orientation, i.e., the direction of the palm, to the group of phonological parameters (Battison 1974; Grosjean 1980) while others defined orientation as a subcategory of handshape (Crasborn \& van der Kooij 1997; Sandler \& Lillo-Martin 2006). 


\begin{tabular}{|c|c|c|c|}
\hline $\begin{array}{l}\text { Grosjean (1980) } \\
\text { and Clark \& } \\
\text { Grosjean (1982) }\end{array}$ & ASL & Gating & $\begin{array}{l}\text { Location and handshape are } \\
\text { identified at about the same time } \\
\text { while movement is identified last. } \\
\text { All parameters are identified faster } \\
\text { when context is provided. }\end{array}$ \\
\hline $\begin{array}{l}\text { Emmorey \& Corina } \\
\text { (1990) }\end{array}$ & ASL & Gating & $\begin{array}{l}\text { Location is identified correctly first } \\
\text { followed by handshape and } \\
\text { movement. }\end{array}$ \\
\hline $\begin{array}{l}\text { Thompson, } \\
\text { Emmorey \& Gollan } \\
(2005)\end{array}$ & ASL & Tip-of-the-fingers & $\begin{array}{l}\text { Information about location and } \\
\text { handshape is retrieved from mental } \\
\text { lexicon while information about } \\
\text { movement is not retrieved. }\end{array}$ \\
\hline $\begin{array}{l}\text { Orfanidou et al. } \\
(2009)\end{array}$ & BSL & $\begin{array}{l}\text { Misperceptions in a sign } \\
\text { spotting task }\end{array}$ & $\begin{array}{l}\text { When identifying non-signs as real } \\
\text { signs, the location parameter is } \\
\text { rarely changed, the handshape } \\
\text { parameter is changed in some case } \\
\text { while the movement parameter is } \\
\text { frequently changed/adapted. }\end{array}$ \\
\hline $\begin{array}{l}\text { Gutiérrez, } \\
\text { Williams, et al. } \\
(2012)\end{array}$ & ASL & $\begin{array}{l}\text { ERP study on sentence } \\
\text { processing }\end{array}$ & $\begin{array}{l}\text { Stronger and broadly distributed } \\
\text { N400 effect is observed for signs } \\
\text { overlapping in their location } \\
\text { parameter compared to unrelated } \\
\text { signs. }\end{array}$ \\
\hline $\begin{array}{l}\text { Baus et al. (2008) } \\
\text { and Baus, Gutiérrez } \\
\& \text { Carreiras (2014) }\end{array}$ & LSC & Picture-sign interference & $\begin{array}{l}\text { Naming is facilitated for overlap in } \\
\text { only handshape, only movement or } \\
\text { both location and movement, but } \\
\text { naming is inhibited for overlap in } \\
\text { only location. }\end{array}$ \\
\hline
\end{tabular}

$\mathrm{BSL}=$ British Sign Language; ASL = American Sign Language; $\mathrm{LSC}=$ Catalan Sign Language

Taken together, the data presented in Table 1 suggest a hierarchy of the individual parameters and their impact on processing, such that the location parameter is prioritized in sign recognition followed by handshape and, lastly, movement. On the other hand, looking at the effects of combined parameters, the overlap in location and movement in signs leads to them being rated more similar and to increased facilitation effects in priming tasks (Hildebrandt \& Corina 2002; Brentari 2006). Thus, the parameters appear to have disparate influences depending on the degree of overlap in other parameters.

Priming studies examine how the response to a stimulus is affected by pre-exposure to a related stimulus. Thus, when a word is preceded by a phonologically related word, the recognition of the second word is typically faster than when it is preceded by an unrelated word (Hillinger 1980; Slowiaczek \& Pisoni 1986). However, there are differences in the speed or accuracy of word recognition based on the degree of overlap between words and the position of overlap within the word (Slowiaczek \& Hamburger 1992; Radeau, Morais \& Segui 1995; Slowiaczek et al. 2000). Phonological priming has been attested for sign languages as well. 
Studies have shown that sign recognition is affected by a preceding phonologically related sign reflected in facilitation or inhibition in recognition of the target sign (see Table 1 for references).

In a lexical decision task, Corina \& Hildebrandt (2002) examined the effects of phonological form-based priming in ASL by presenting sign/sign and sign/non-sign pairs varying in their phonological overlap, i.e., unrelated, sharing the same location or sharing the same movement. The data showed that participants were slower to reject signs that overlapped phonologically with the prime. Using the same task, Carreiras et al. (2008) presented sign/sign and sign/non-sign pairs in Spanish Sign Language (LSE) sharing either the same handshape, the same location or being phonologically unrelated. They observed slower response times for signs sharing location, but no effect for shared handshape. Non-signs showed faster response times for shared handshape, but no effect for shared location. In an ERP study, Gutiérrez, Müller, et al. (2012) investigated sign recognition in LSE using similar stimuli and found higher N400 amplitude for signs with shared location, but a more negative going potential between 600 and $800 \mathrm{~ms}$ for non-signs with shared handshape. They explained this effect based on lexical competition. The identification of the location parameter itself is quite fast due the presence of fewer possible locations in general. However, this results in more competitors at each specific location and increases competition among them, which leads to inhibition reflected in slower reaction times and a higher N400 amplitude. In contrast, the recognition of the handshape parameter is more difficult due to the high degree of variability between the relatively large number of different handshapes. This results in increased processing costs reflected in a later ERP effect for non-signs, but leads to facilitation for signs with lowfamiliarity due to there being fewer competitors.

In contrast, ERP data on ASL showed reduced N400 amplitude for phonologically related prime-target pairs suggesting a facilitation effect in both implicit, i.e., reading words whose ASL translations are phonologically related, and explicit priming contexts (Meade et al. 2017; Meade et al. 2018). While Gutiérrez, Müller, et al. (2012) investigated pairs overlapping in one parameter, Meade et al. (2018) presented pairs overlapping in two out of three parameters, which might explain the opposing direction of effects reported in these studies.

Similarly, Dye \& Shih (2006) investigated phonological priming effects in native signers of BSL for signs overlapping in one or more phonological parameters. They reported no effect for sign/sign pairs sharing handshape, but faster reaction times for sign/sign pairs sharing location and sharing both location and movement. The authors suggested that the effect was evoked by the interaction between signs in the lexicon. Thus, once a sign is activated, spreading activation leads to activation of related signs sharing the same location and movement parameter. Dye \& Shih (2006) concluded that lexical access was initialized by combined location and movement parameters for native signers. In contrast, Mayberry \& Witcher (2005) did not observe any effects for native signers using the same task, which they speculated might be due to ceiling effects in their baseline condition. However, they did not separately analyze minimal pairs with regards to particular parameters overlapping, such that averaging across the different minimal pair types may obscure potential differences. For German Sign Language (Deutsche Gebärdensprache: DGS), Hosemann (2015) reported an overall phonological 
priming effect in an ERP study, but did not present a more detailed analysis based on which parameters were shared by the minimal pairs.

Overall, the results presented in this section provide evidence for a phonological priming effect in sign languages. Even though the findings vary with regard to the influence of different parameters and the direction of effects, they show that signs sharing either location or both location and movement evoke different effects relative to other parameter combinations.

\subsection{Eye tracking studies in sign languages}

The eye tracking technique, i.e., recording participants' eye movements while they perceive a stimulus, is widely used in spoken language research to investigate processing of the phonological content of the input. Eye movements represent mental processes taking place during stimulus processing, i.e., eye-mind hypothesis (Just \& Carpenter 1980). In sign language research, this method was initially used to investigate whether signers show systematic eye movements while perceiving or producing sign language (Thompson, Emmorey \& Kluender 2006; Emmorey, Thompson \& Colvin 2009; Hosemann 2011).

Up to now, only two studies have combined the eye tracking method for sign language research with the classical Visual World Paradigm (VWP) (Cooper 1974; Tanenhaus et al. 1995 ) to study sign language comprehension in adult sigerns. ${ }^{3}$ In the first study, Lieberman et al. (2015) presented participants with videos in ASL, displaying a single sign in the center of a screen surrounded by four pictures. In the unrelated condition, the target picture, i.e., the picture participants were asked to click on, was presented with three completely unrelated distractors. In phonologically related trials, distractors formed minimal pairs with the target sign, overlapping in two of three phonological parameters. Participants preferentially fixated phonological distractors compared to the unrelated distractors from $600 \mathrm{~ms}$ onwards: signers shifted their gaze towards the target picture even before the sign ends. The authors interpreted these results suggesting that phonological parameters were activated quite early and activated all possible candidates in the mental lexicon sharing same parameters, leading to lexical competition.

The second study was conducted by Thompson et al. (2013) in BSL. They simultaneously presented a video of a person signing sentences containing the carrier phrase $I$ see... followed by a target sign, centrally located on a screen surrounded by four pictures. Participants were asked to indicate whether the target sign matched one of the displayed pictures. Participants fixated target images whose corresponding BSL signs overlapped in both location and movement more than unrelated pictures. Additional analyses found differences in looking behavior between unrelated and location-movement overlap trials and a later effect for handshape-movement pairs. There was no difference across the time course for handshapelocation pairs. The effect observed for location-movement pairs is in line with previous findings using different tasks and underlined the peculiar role of this parameter combination for lexical

3. Both studies examined semantic effects as well. However, these results are not presented here because they are not of interest for the purpose of the current study. 
access in sign languages. The later effect of handshape-movement pairs was interpreted as reflecting post-lexical processes where possible competitors are retrieved prior to the final decision on target identification. The authors concluded that lexical access in sign languages is driven by perceptual salience rather than the temporal order of accessible phonological parameters.

Both studies (see also Lieberman, Borovsky \& Mayberry (2017)) demonstrated that the VWP can be applied in sign language research as well. Lieberman et al. (2015) reported an overall effect of phonological competition for the processing of signs presented in isolation, whereas Thompson et al. (2013) presented a more fine-grained analysis based on groups of signs, embedded in a carrier phrase, sharing different combinations of phonological parameters. They showed that the overlap of location and movement parameters triggered different responses relative to other parameter combinations (see Table 2 for an overview of phonological priming and eye tracking studies). This is in line with the studies discussed in section 1.1. 
Table 2. Overview of studies using different methods to investigate phonological priming in sign languages

\begin{tabular}{|c|c|c|c|c|c|c|c|c|}
\hline \multirow{2}{*}{\multicolumn{2}{|c|}{ Task }} & \multirow{3}{*}{$\begin{array}{c}\text { Language } \\
\text { ASL } \\
\text { (Corina \& } \\
\text { Hildebrandt 2002) }\end{array}$} & \multicolumn{6}{|c|}{ Results for overlap of } \\
\hline & & & Handshape & Location & Movement & $\begin{array}{l}\text { Handshape } \& \\
\text { Location }\end{array}$ & $\begin{array}{l}\text { Location\& } \\
\text { Movement }\end{array}$ & $\begin{array}{l}\text { Movement \& } \\
\text { Location }\end{array}$ \\
\hline \multirow{9}{*}{ 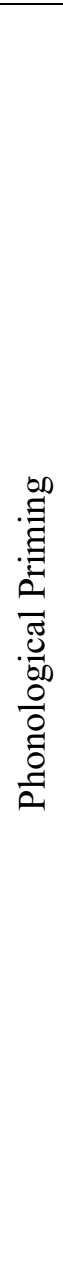 } & \multirow{4}{*}{ Lexical decision } & & -- & inhibition & inhibition & -- & -- & -- \\
\hline & & $\begin{array}{c}\text { ASL } \\
\text { (Mayberry \& Witcher } \\
\text { 2005) }\end{array}$ & -- & -- & -- & \multicolumn{3}{|c|}{ no effect (for native signers) } \\
\hline & & $\begin{array}{c}\text { LSE } \\
\text { (Carreiras et al. 2008) }\end{array}$ & no effect & inhibition & -- & -- & -- & -- \\
\hline & & $\begin{array}{c}\text { BSL } \\
\text { (Dye \& Shih 2006) }\end{array}$ & no effect & facilitation & no effect & no effect & facilitation & no effect \\
\hline & $\begin{array}{c}\text { ERP } \\
\text { (sign/sign \& sign/non- } \\
\text { sign pairs })\end{array}$ & $\begin{array}{c}\text { LSE } \\
\text { (Gutiérrez, Müller, et } \\
\text { al. 2012) }\end{array}$ & inhibition & inhibition & -- & -- & -- & -- \\
\hline & $\begin{array}{c}\text { ERP } \\
\text { (prime-target pairs within } \\
\text { sentences) }\end{array}$ & $\begin{array}{c}\text { DGS } \\
(\text { Hosemann 2015) }\end{array}$ & -- & -- & -- & \multicolumn{3}{|c|}{$\begin{array}{c}\text { facilitation } \\
\text { (no analysis based on parameter combinations) }\end{array}$} \\
\hline & $\begin{array}{c}\text { ERP } \\
\text { (prime-target pairs) }\end{array}$ & $\begin{array}{c}\text { ASL } \\
\text { (Meade et al. 2018) }\end{array}$ & -- & -- & -- & \multicolumn{3}{|c|}{$\begin{array}{c}\text { facilitation } \\
\text { (no analysis based on parameter combinations) }\end{array}$} \\
\hline & \multirow{2}{*}{ Eye tracking } & $\begin{array}{c}\text { BSL } \\
\text { (Thompson et al. } \\
\text { 2013) }\end{array}$ & -- & -- & -- & $\begin{array}{l}\text { later effect of } \\
\text { facilitation }\end{array}$ & facilitation & no effect \\
\hline & & $\begin{array}{c}\text { ASL } \\
\text { (Lieberman et al. } \\
\text { 2015) }\end{array}$ & -- & -- & -- & facilitation & inhibition & no effect \\
\hline
\end{tabular}

ASL = American Sign Language; LSE = Spanish Sign Language; BSL = British Sign Language; DGS = German Sign Language 


\subsection{The present study}

The current study investigated whether a phonological priming effect could be observed for DGS using a modified version of the VWP combined with the eye tracking technique. Moreover, we examined whether signs sharing specific phonological parameters differentially influenced processing reflected in systematic differences in participants' eye-movements in the parameter combinations presented. Extending previous work, especially by Thompson et al. (2013), we also examined whether eye tracking could be used to investigate processing at the sentence level using natural signed sentences, thereby examining natural language processing. Therefore, in contrast to Thompson et al. (2013) and Lieberman et al. (2015), our study presented prime-target sign pairs embedded in naturally signed sentences (see examples 1-3 below in section 2.2). Prime and target formed a minimal pair overlapping in two phonological parameters but differing in the third. ${ }^{4}$ This resulted in the following three priming parameter conditions labelled according to the overlap of parameters (Figure 1): (i) LOC+MOV condition, i.e., sharing location and movement; (ii) $\mathrm{HS}+\mathrm{MOV}$ condition, i.e., sharing handshape and movement, and (iii) HS+LOC condition, i.e., sharing handshape and location. Additionally, a sentence containing an unrelated prime-target sign pair was constructed for each of the priming conditions. Each video was presented along with two pictures displaying the target and an unrelated distractor.

4. The definition of a minimal pair is adopted from research on spoken languages. To create a minimal pair in spoken languages, one phoneme in a word is substituted to create a new word with a different meaning. From a phonological point of view, this word pair only differs in a single phoneme (Kenstowicz \& Kisseberth 1979; Crystal 2008). 


\section{Condition}
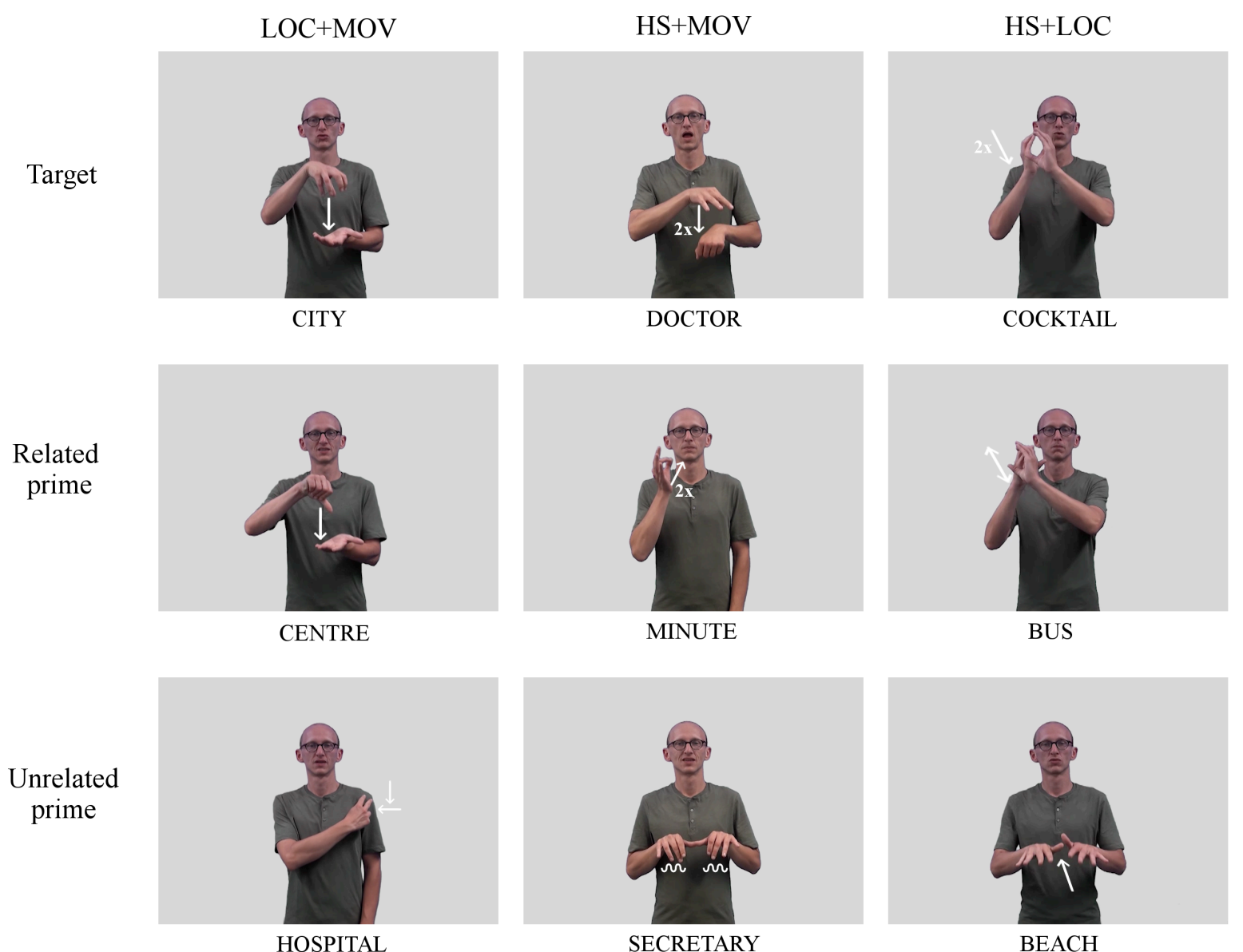

Figure 1. Overview of prime-target sign pairs with examples from the stimuli: minimal pairs sharing location and movement (left column), handshape and movement (central column) and handshape and location parameters (right column). In the priming condition, the target (upper row) and the related prime (central row) are combined. In the unrelated condition, the unrelated prime (bottom row) is combined with the target.

We recorded participants' eye movements as they looked at the pictures and videos presented simultaneously on a screen. We expected that participants will show increased fixations to the target in the primed condition compared to the unrelated condition for each parameter variation. We were particularly interested in how target fixations differ across the different parameter conditions, as this would inform us with regard to the influence of these parameters on sign recognition.

\section{Methods}

\subsection{Participants}

Twenty-six deaf native signers of DGS participated in the experiment. In total, three participants were excluded from the analysis either due to calibration failure (2) or due to extensive trackloss in the recorded data (1). The remaining 23 participants (11 female, 12 male) 
had a mean age of 33 years (range: 20 - 58 years) and at least high school education level. Twenty-one participants had deaf parents or exposure to DGS before the age of 5, whereas two were exposed to DGS at the ages of 8 and 15 years. However, these two had access to another sign language before and stated DGS to be their primary language of use for more than 20 years. Moreover, excluding these two participants did not lead to changes in the results. Participants were volunteers and got paid for their participation. Before starting the experiment, all subjects were informed about the procedure and gave written consent for their participation. The experiment was approved by the Ethics Committee of the Institute of Psychology.

\subsection{Material}

Ten sentences were constructed for each condition resulting in 60 stimulus sentences. However, for the HS+MOV condition, one minimal pair and its unrelated counterpart were excluded prior to the testing of the experiment because of an incorrect combination of signs in the stimulus video. Thus, 58 stimulus sentences remained for data analysis.

Sentences (see examples 1 to 3 below and the Appendix for a full list of the stimulus material) started with a locative, temporal, benefactive, adverbial or topic expression followed by the prime, an intervening sign, the target, and the predicate in sentence-final position (which might be accompanied by a modal or an adverbial). To avoid their occurrence in sentence-initial and sentence-final position, at least one sign preceded the prime and followed the target sign. A function sign, e.g., always, or, IX, was inserted between prime and target to give participants time to process the prime before seeing the target. Content words were avoided as intervening signs since they could evoke semantic associations and therefore interfere with the priming effect. In the priming conditions, all sentences contained a phonologically related minimal pair sharing two out of three phonological features and differing in the third feature as described above. In contrast, prime-target sign pairs in the unrelated conditions were completely phonologically unrelated, thus neither sharing any features in DGS nor orthographically in their German translation to avoid bimodal priming, i.e., priming in the second language (Morford et al. 2011; Ormel et al. 2012; Hosemann et al. 2020; Kubus et al. 2015). Moreover, sign pairs in all conditions were not semantically related. Using the Noun Associations for German database by Melinger \& Weber (2006), we determined sematic associations between target signs and any preceding content sign. An analysis showed no significant difference between priming and unrelated conditions $(W=3, p>.1)$. Sentences were structurally identical for each prime-target sign pair in the priming and the unrelated condition. Targets were kept stable for both conditions while all other content words differed. Signs only occurred once as prime or target.

$$
\text { LOC+MOV condition } 5
$$

a. Priming

\footnotetext{
5. Notational conventions: signs are glossed in small caps. A hyphen between signs indicates that more than one word is needed to gloss a single sign. Prime-target sign pairs are marked in bold. In the examples discussed below, IX1 denotes the first person singular pronoun, IX is a demonstrative and POSS1 describes the first person possessive pronoun. Note that DGS uses SOV as its primary word order (Happ \& Vorköper 2006).
} 
JUST IX 1 CENTRE IX CITY VISIT.

'I just visited the center of the city.'

b. Unrelated

YESTERDAY IX 1 HOSPITAL IX CITY GO-TO.

'Yesterday, I went to the hospital of the city.'

(2) HS+MOV condition

a. Priming

TWENTY MINUTES IX DOCTOR COME.

'In twenty minutes, a doctor will come.'

b. Unrelated

EVERY-DAY SECRETARY IX DOCTOR SUPPORT.

'Every day, the secretary supports the doctor.'

(3) HS+LOC condition

a. Priming

YESTERDAY EVENING POSS 1 FRIEND BUS IX COCKTAIL DRINK.

'Yesterday evening, my friend drank a cocktail in the bus.'

b. Unrelated

HOLIDAYS IX POSS 1 FATHER BEACH IX COCKTAIL ENJOY.

'During the holidays, my father enjoys a cocktail at the beach.'

The material was discussed and recorded with the help of a male deaf native signer of DGS using a Sony HDR-CX550VE camcorder. We did not control for the use of nonmanuals. However, the signer was instructed to reduce body movements such as body lean as well as to sign slower than their usual signing speed while maintaining a natural occurring speed. This was to allow participants increased time to process the presented stimuli while maintaining the duration of the videos more or less the same across all trials. Videos were cut and processed with the video editing software Adobe Premiere Pro CS6 such that the signer remained motionless for $1000 \mathrm{~ms}$ at the beginning and $1500 \mathrm{~ms}$ at the end of each video. Additionally, the background color of each video was changed to grey so that the background color of the video and the presented pictures was identical to avoid possible effects by different background colors. The videos were not modified further. Videos had a size of $732 \times 550$ pixels and a duration of $7720 \mathrm{~ms}$ - $12880 \mathrm{~ms}$ (mean duration: $10434 \mathrm{~ms}$ ). Paired samples t-test comparing target sign durations revealed no significant difference between priming and unrelated conditions as well as based on parameter conditions within the priming and unrelated conditions.

Additionally, a set of five practice sentences with the same structure was developed. Two sentences contained a minimal pair and three contained an unrelated sign pair. The minimal pairs used in the practice sentences were not used in the sentences during the 
experiment. These sentences were recorded and processed the same way as the stimulus material and were presented prior to the experiment to familiarize participants with the procedure.

Twenty-nine picture sets served as stimulus pictures. These were color photo-realistic images presented on a grey background with a size of 400x400 pixels. Two pictures were always presented at the same time. One of them showed the target and the other a distractor not related semantically, phonologically (neither in DGS nor in its written German translation) or in shape or size of the depicted objects. The same combinations of target and distractor images were shown in the priming and unrelated condition counterbalanced for their position onscreen. To ensure the unambiguity of the images independent of language modality, we conducted a picture-naming task with native speakers of German, in an online questionnaire using Google Forms (Google Inc.). Stimulus pictures for the present study and another eye tracking study (not relevant here) were tested in this questionnaire. For each noun, two images were presented to allow choosing the clearest picture resulting in 216 images in total divided into four lists containing 54 images each. Pictures for the same noun never occurred in the same list. Participants were instructed to name the image they see fast and spontaneously with one word. In total 101 participants (79 female, 22 male, mean age: 25 years) filled in the questionnaire. Eight participants were excluded prior to evaluation because they were not native speakers of German. For each noun, the answers to both of the presented pictures were compared. The image with the most exact and correct responses was chosen.

\subsection{Procedure}

Prior to testing, participants were informed about the eye tracking method and the procedure of the experiment. All explanations were given in DGS and written form to ensure that the information was accessible to all participants. Participants filled in a demographics form and gave written and signed consent prior to the start of the experiment. After finishing the experiment, participants were informed about the goal of the study.

Participants were seated at a table in front of a 17-inch computer screen with a resolution of 1280x1024 pixels. They were instructed to place their head on the chinrest to reduce head movements. The eye tracking camera was positioned right in front of the computer screen with $50-70 \mathrm{~cm}$ distance from the participant's face and adjusted manually to obtain a good image of the participant's eye. A PC computer was used to present the stimuli using the Eyelink Experiment Builder Software, Version 1.10.165 (SR Research Ltd.). At the beginning of the experiment, an introduction video in DGS explained the procedure followed by a short practice session to familiarize participants with the structure of the experiment. Participants could clarify remaining questions after the practice session. Then the actual experiment started with a ninepoint calibration sequence. Additionally, a one-point drift correction, manually accepted by the experimenter, was performed before each trial. Stimuli were shown in two blocks with 29 trials each. Between the blocks, participants were given a break. In that time, they could relax their eyes and their body by removing the head from the chinrest. Therefore, the calibration sequence was repeated before continuing with the second block. 
Trials started with the presentation of the pictures on the top of the screen for $3000 \mathrm{~ms}$ (Figure 2). Following that, the stimulus video appeared on the screen below the pictures. The video disappeared after the stimulus video ended, i.e., when the hands of the signer were put down, and only the pictures remained on the screen for $2000 \mathrm{~ms}$. Then the next trial started automatically. Videos were presented at the bottom of the screen since sentences contained pointing signs that might be interpreted as direct pointings to the pictures and thus might interfere with the study. An Eyelink 1000 Desktop Mount (SR Research Ltd.) with a remote eye-tracker was used to automatically track and record the eye-movements with a sampling rate of $500 \mathrm{~Hz}$. Recording for each trial started with the initial presentation of the pictures and continued during the presentation of the video until the pictures disappeared. The data were binned offline into $40 \mathrm{~ms}$ sequences.

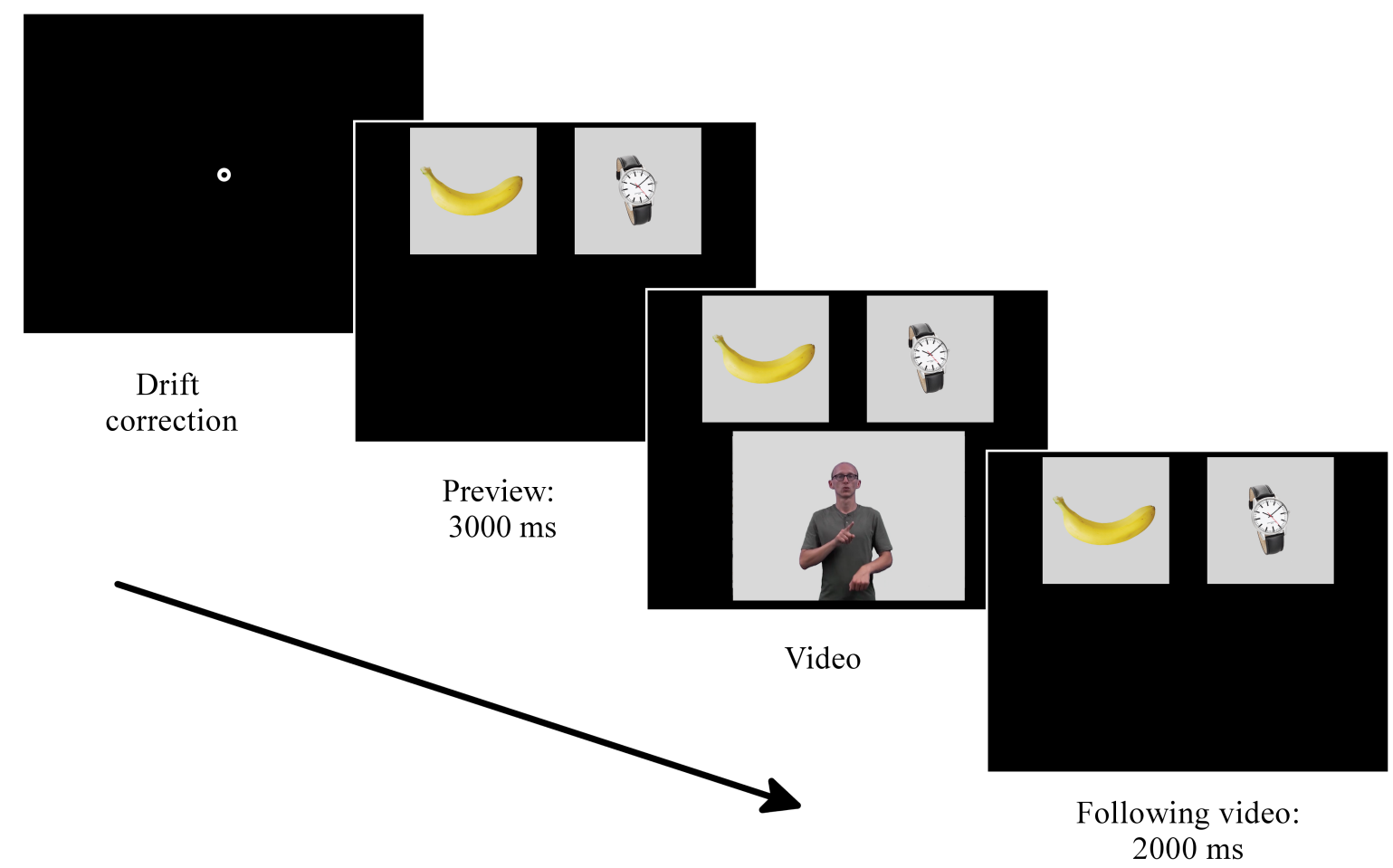

Figure 2. Structure of a single trial.

Four different randomization lists were prepared for stimulus presentation. Each list contained all sentences, only differing in order of presentation. For the first list, sentences were grouped into two blocks manually to avoid consecutive trials of the same minimal pair in the priming and unrelated condition. Each block contained ten trials per parameter condition - five in the priming and five in the unrelated condition. The position of the target was counterbalanced. For the second list, the same order of blocks was used, but positions of the images were reversed. In the third and fourth list, the order of the blocks was reversed such that the second block was presented first to account for order of presentation effects. Within each block the order of trials was randomized on-line by the experimental software with a maximum occurrence of two consecutive trials in the same condition (priming and unrelated). 


\section{Results}

The eye movement data were analyzed according to fixations to three areas of interest (AOIs), i.e., the video and the pictures of target and distractor using the eyetrackingR package (Dink \& Ferguson 2015) in R (Version 3.5.0). Mean proportion of fixations to the target (PTL) in each parameter condition comparing the priming and unrelated condition are plotted in Figure 3 . The PTL is defined as fixations to the target divided by the sum of fixations to all AOIs (target/(target + distractor + video)). Since participants almost exclusively fixated the video during the video presentation, and only moved to the target sign upon presentation of this sign, earlier time windows were not considered in the analysis. Therefore, the time course does not represent the whole video, but is time-locked and aligned to the start of the target sign within each video. Since naturally signed sentences were used, the position of the target sign varied across the sentences and occurred at a different time point in each video. Therefore, the onset of the target sign had to be determined manually by two independent coders. Sign onset is defined as the first frame of a sign where target handshape and hand orientation reached their target location and hands are about to start the path movement toward their final position (Hosemann et al. 2013). Thus, the graph shows the time course starting from the onset of the target sign until the end of the video (range: $2080-3880 \mathrm{~ms} ; M=2948 \mathrm{~ms}$ ) and $1500 \mathrm{~ms}$ following the offset of the video. As can be seen in the figure, looks to the target started to increase at around $1000 \mathrm{~ms}$ following target sign onset, especially for the location parameter condition. Thus, participants started fixating the target picture only following the presentation of the target sign since these had a mean length of $528 \mathrm{~ms}$ (range: $160-880 \mathrm{~ms}$ ). 


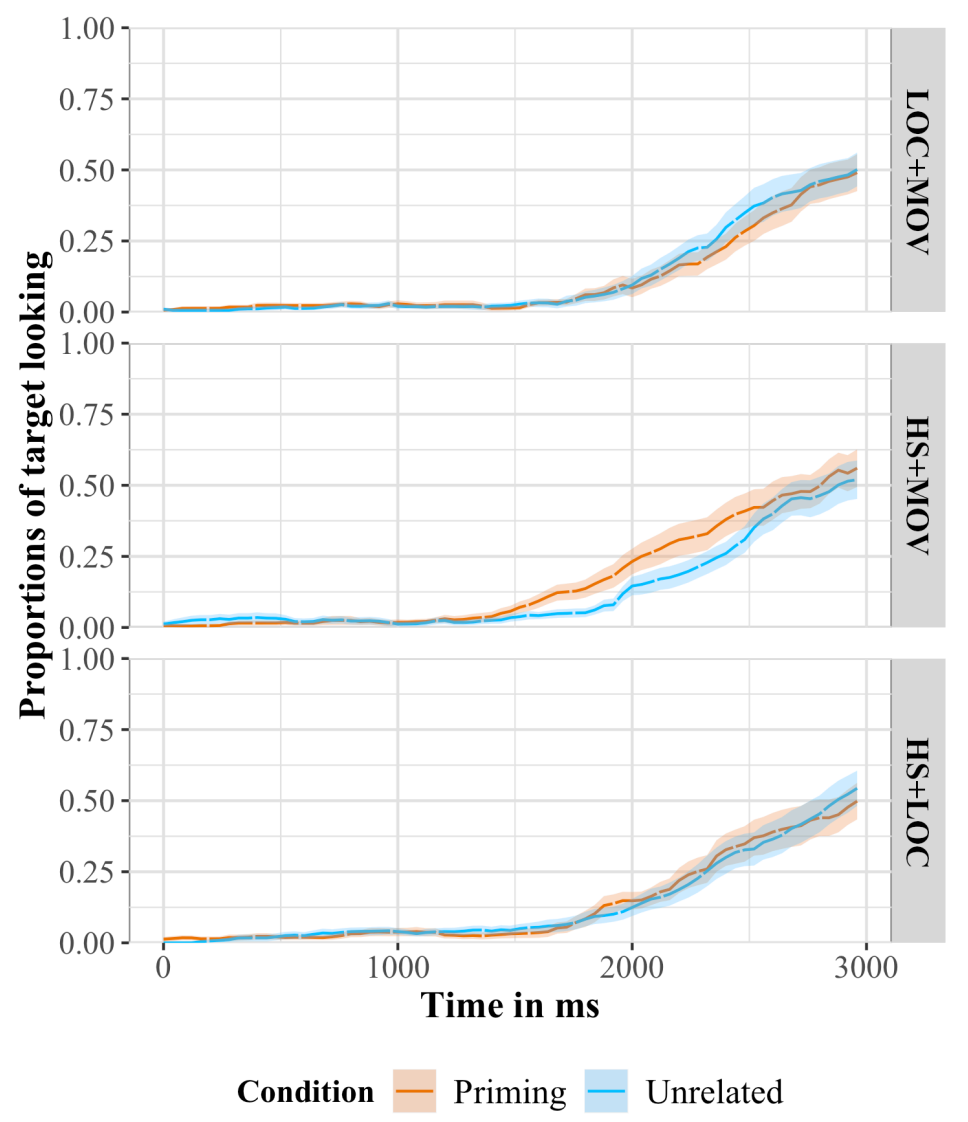

Figure 3. Mean proportion of target looking across time for each parameter condition (from top to bottom: location and movement, handshape and movement, handshape and location). The priming (orange) and unrelated (blue) conditions are shown as lines surrounded by shaded areas indicating standard error.

For the analysis, mean proportion of target looking was examined across a time window of $2000 \mathrm{~ms}$ (Hanna \& Tanenhaus 2004), analyzing the data between 1000 - $3000 \mathrm{~ms}$ following target sign onset (Figure 4). The onset of the analysis window was chosen based on the duration of the longest target sign $(880 \mathrm{~ms})$, since the length of the target sign varied between the stimulus sentences, and adding a $100 \mathrm{~ms}$ for initiating a saccade to the target picture. 


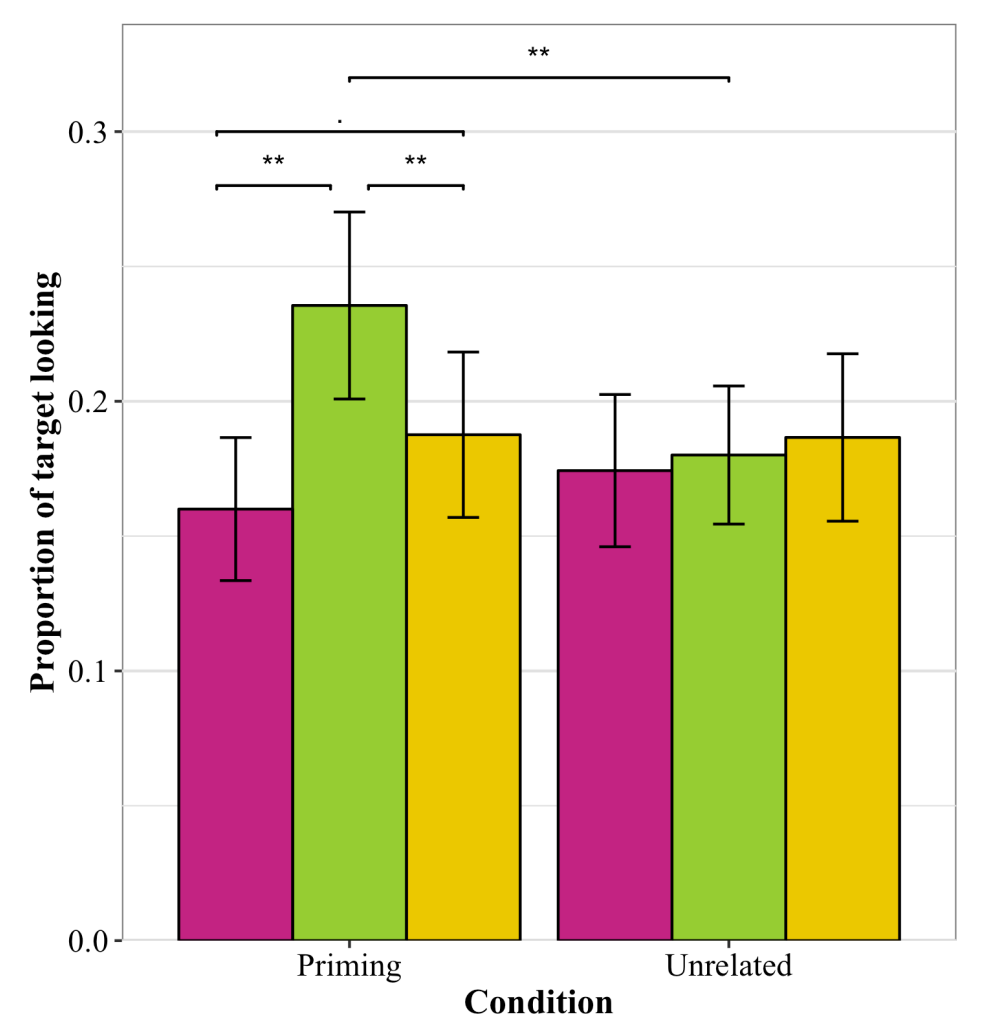

Parameter $\square$ LOC+MOV $\square$ HS+MOV $\square$ HS+LOC

Figure 4. Mean proportion of target looking for priming and unrelated conditions for each parameter condition (pink = location and movement; green $=$ handshape and movement, yellow $=$ handshape and location) between 1000 - $3000 \mathrm{~ms}$ following target sign onset. Error bars represent standard errors. Asterisks above bars indicate significance levels between bars: $p<.08$

$* p<.05 ; * * p<.01$

Running a 2x3 ANOVA with the factors condition (priming, unrelated) and parameter condition $(\mathrm{LOC}+\mathrm{MOV}, \mathrm{HS}+\mathrm{MOV}, \mathrm{HS}+\mathrm{LOC})$ revealed a main effect of parameter condition $(F(2,44)=$ $5.81 ; p=.006)$ and an interaction between the factors $(F(2,44)=4.99 ; p=.011)$. Paired samples t-tests comparing priming and unrelated condition for each parameter revealed a significant difference in the HS+MOV parameter condition $(t(22)=3.20 ; p=.004)$ with higher PTL in the priming condition compared to the unrelated condition. There was no difference between conditions for LOC+MOV and HS+LOC parameter conditions $(p>.1)$. Further, parameter conditions were compared using paired samples t-tests within priming and unrelated condition. This analysis revealed no difference between parameter conditions in the unrelated condition $(p>.1)$. However, comparisons in the priming condition revealed a significant difference between HS+MOV and HS+LOC parameter conditions $(t(22)=3.12 ; p=.005)$, as well as between HS+MOV and LOC+MOV parameter conditions $(t(22)=3.39 ; p=.003)$ with, in both cases, more looks to the target in the HS+MOV parameter condition. Comparing HS+LOC and LOC + MOV parameter conditions showed a near-significant difference $(t(22)=2.00 ; p=.057)$ with more looks in the HS+LOC parameter condition. This resulted in a hierarchy for the different parameter conditions with the most looks in the HS+MOV parameter condition followed by HS+LOC and the fewest looks in the LOC+MOV parameter condition. Additional 
analyses on first fixation latency to the target AOI revealed a similar picture with the shortest latency in the HS+MOV parameter condition.

\section{Discussion}

The current study investigated whether a phonological priming effect at the sentence level in DGS can be observed and how variation in the phonological relatedness of sign pairs, i.e., which parameters they shared, influenced this effect. We examined this by recording participants' eyemovements while presenting them with videos, containing either related or unrelated primetarget sign pairs embedded in sentences, and two pictures, i.e., target and distractor, using a modified version of the VWP. Overall, results revealed a phonological priming effect. However, variation in phonological relatedness, i.e., the specific phonological parameters that overlap in a prime-target sign pair, had an impact on this effect in different ways since the parameters under investigation evoked distinct effects. Concerning the methodology, the experiment showed that priming effects in sign languages can be investigated by using eye tracking methodology.

The data presented in this study provide additional support for the hypothesis that phonological parameters impact sign processing differently. Sign processing is facilitated for sign that share the same handshape and movement. A more detailed analysis of the priming conditions suggested a taxonomy for the three parameter conditions with the HS+MOV parameter showing proportionally the most and the LOC+MOV parameter showing the fewest looks to the target picture, whereas the HS+LOC parameter fell in between, i.e., HS+MOV > HS + LOC $>$ LOC + MOV. These findings are in line with Lieberman et al. (2015), who also observed similar effects for their phonological condition (as described in section 1). While the authors did not report differences within the phonological condition for the different groups of minimal pairs, analysis of the saccade latency to the target showed a marginal main effect for phonological parameter for a combined group of native and late signers. Participants were the fastest for minimal pairs sharing handshape and movement and the slowest when the pairs shared location and movement, whereas pairs sharing handshape and location fell in between (the data and the $\mathrm{R}$ code underlying this analysis are available at: DOI: 10.17605/OSF.IO/XRBSE). Taken together, the results from both studies support the effect of a shared handshape and movement parameter. This is in contrast with previous studies that observe diverging effects for signs sharing location or location and movement (see section 1.1 $-1.3)$.

Nevertheless, the different approaches and results of previous research and our study are not contradictory, they are rather supporting each other. Carreiras et al. (2008) and Gutiérrez, Müller, et al. (2012) both observed facilitation for overlap in handshape and inhibition for location overlap explaining this difference based on the concept of lexical competition. Overall, there are more possibilities for different handshapes than locations (for ASL (Liddell \& Johnson 1989) and for DGS (Pfau 1997; Perniss 2007)) leading to fewer signs 
sharing the same handshape, but more signs sharing the same location. Thus, identifying the correct sign when overlapping in the location parameter requires more effort and time due to more competitors. In contrast, identification is faster and easier when there is an overlap in the handshape parameter because of fewer competitors. This offered a possible explanation of our results as well. Both conditions, where signs shared the same handshape, were faster than the condition that differed in handshape suggesting that an overlap in the handshape parameter enhances sign processing due to faster lexical processing. However, since sign pairs always shared two out of three parameters, not just one, this explanation has to be restricted and be seen with caution.

Running simulations in a computational model with a spreading activation architecture, Caselli \& Cohen-Goldberg (2014) discarded the notion of lexical competition to explain the differences between the handshape and location parameter. Using the computational model of word processing proposed by Chen \& Mirman (2012), they examined which modality-specific properties might account for the differences between the two parameters. Changes in the actual number of lexical neighbors did not produce the observed differences. Thus, it did not make a difference whether a sign had one or five neighbors. However, the model generated the expected results when implementing information about differences in timing and robustness of encoding reflected in the sub-lexical frequency. Timing refers to the point in time when a parameter is identified and, as described in section 1.1, the location parameter is identified before the handshape parameter (Grosjean 1980; Emmorey \& Corina 1990). Caselli \& CohenGoldberg (2014) concluded that the temporal order of parameter identification influenced a sign's perception due to stronger activation. When a parameter, i.e., sub-lexical feature, is activated, it sends its activation to all neighbors, i.e., signs sharing this feature. If this activation starts early, as in case of the location parameter, all competitors collect this activation for a longer time and are more robustly activated, which increases competition and leads to inhibition. In contrast, if activation starts later, as with the handshape parameter, there is less time to summate activation and competitors are less activated, which leads to less competition, i.e., facilitation. Caselli \& Cohen-Goldberg (2014) defined robustness of encoding based on the sub-lexical frequency, which they describe as similar to neighborhood density due to the definition of neighbors sharing a feature, leading to different levels of resting activation for each phonological parameter. Looking at previous studies, location indeed seems to be encoded differently since it is, e.g., less prone to tip-of-the-fingers (phenomena) and acquired earlier than handshape (Siedlecki Jr \& Bonvillian 1993; Thompson, Emmorey \& Gollan 2005; Morgan, Barrett-Jones \& Stoneham 2007). Thus, if a parameter is encoded robustly, it has a higher sub-lexical frequency and a higher resting state level, which leads to strongly activated competitors and inhibition. On the other hand, a less robustly encoded feature has a lower resting state level so that competitors are less activated, which leads to facilitation. The inhibition effect for signs overlapping in the location parameter in previous literature suggests that location must be encoded more robustly while the facilitation effect for sharing the same handshape parameter suggests a less robust encoding for this parameter. According to Caselli \& Cohen-Goldberg (2014), both explanations were equally likely since varying either timing or sub-lexical frequency lead to the different effects for handshape and location observed in 
various experimental studies. Thus, sub-lexical properties accounted for the observed difference effects of handshape and location while lexical properties could not. Equally, we suggest that it is likely that sub-lexical properties played an important role in the effects reported in the current study. However, this raises the question whether the observed effect is based on the phonological parameters that differ or are shared between signs.

So far, the definition of the parameter conditions in the current study was based on the notion of minimal pairs in spoken languages. These were defined as word pairs that only differ in a single phoneme while all remaining phonemes are the same (Kenstowicz \& Kisseberth 1979; Crystal 2008). However, phonemes and phonological features in spoken languages are not directly comparable to phonological parameters in sign languages possibly leading to differences in defining minimal pairs in these two language modalities. For sign languages, Caselli \& Cohen-Goldberg (2014) propose a different account that is based on signs sharing one phoneme. In our study, we only included signs that share two out of three phonological parameters, but no signs overlapping a single parameter. Nevertheless, this taxonomy may allow for improved understanding of phonological parameters and their contribution to sign recognition revealing a new potential hierarchy based on the position of single parameters within the parameter combinations. The parameter occurring at the top was the handshape parameter suggesting that it should be seen as the most important cue in sign recognition. Then, the movement parameter followed, whereas the location parameter took the last position. Hence, the data suggest that sharing the same handshape parameter facilitated sign recognition whereas a shared location parameter seemed to slow down recognition. To verify the proposed hierarchy, future research is required to test signs overlapping in a single parameter.

\section{Conclusion}

From a methodological perspective, the study showed that eye tracking is an appropriate measure to investigate phonological priming effects for sign pairs embedded in natural sentences. Further, the current study provided additional evidence that sign languages are processed on a phonological level similar to spoken languages and contributed to the understanding of factors influencing sign recognition and processing. The data suggested differences in the contribution of phonological parameters to sign recognition. Caselli \& CohenGoldberg (2014) explanations based on the timing and sub-lexical frequency of particular phonological parameters could be applied to our data as well, suggesting that processing of sublexical features drive the effects observed in the current study. Nevertheless, we should keep in mind that signs in each parameter conditions always shared two phonological parameters. Thus, to validate the suggested hierarchy for single parameters contributing to sign recognition, the current study needs to be repeated testing sign pairs sharing only one parameter. This would help to clarify the status of each phonological parameter.

\section{References}


Battison, Robbin. 1974. Phonological deletion in American Sign Language. Sign language studies 5(1). 1-19. doi:10.1353/sls.1974.0005.

Baus, Cristina, Eva Gutiérrez \& Manuel Carreiras. 2014. The role of syllables in sign language production. Frontiers in Psychology 5(1254). doi:10.3389/fpsyg.2014.01254.

Baus, Cristina, Eva Gutiérrez-Sigut, Josep Quer \& Manuel Carreiras. 2008. Lexical access in Catalan Signed Language (LSC) production. Cognition 108(3). 856-865. doi:10.1016/j.cognition.2008.05.012.

Brentari, Diane. 2006. Effects of language modality on word segmentation: An experimental study of phonological factors in a sign language. In Louis Goldstein, D.H. Whalen \& Catherine T. Best (eds.), Laboratory Phonology, vol. 8, 155-164. Berlin, Germany: De Gruyter Mouton.

Carreiras, Manuel. 2010. Sign Language Processing. Language and Linguistics Compass 4(7). 430-444. doi:10.1111/j.1749-818X.2010.00192.x.

Carreiras, Manuel, Eva Gutiérrez-Sigut, Silvia Baquero \& David P. Corina. 2008. Lexical processing in Spanish Sign Language (LSE). Journal of Memory and Language 58(1). 100-122. doi:10.1016/j.jml.2007.05.004.

Caselli, Naomi K. \& Ariel M. Cohen-Goldberg. 2014. Lexical access in sign language: a computational model. Frontiers in Psychology 5(428). doi:10.3389/fpsyg.2014.00428.

Chen, Qi \& Daniel Mirman. 2012. Competition and cooperation among similar representations: toward a unified account of facilitative and inhibitory effects of lexical neighbors. Psychological Review 119(2). 417-430. doi:10.1037/a0027175.

Clark, Lorene E. \& François Grosjean. 1982. Sign recognition processes in American Sign Language: The effect of context. Language and speech 25(4). 325-340. doi:10.1177/002383098202500402.

Cooper, Roger M. 1974. The control of eye fixation by the meaning of spoken language: A new methodology for the real-time investigation of speech perception, memory, and language processing. Cognitive Psychology 6(1). 84-107. doi:10.1016/00100285(74)90005-x.

Corina, David P. \& Ursula C. Hildebrandt. 2002. Psycholinguistic investigations of phonological structure in ASL. In Richard P. Meier, Kearsy Cormier \& David QuintoPozos (eds.), Modality and structure in signed and spoken languages, 88-111. New York, NY: Cambridge University Press.

Crasborn, Onno \& Els van der Kooij. 1997. Relative orientation in sign language phonology. In J. Coerts \& H. de Hoop (eds.), Linguistics in the Netherlands 1997, 37-48. Amsterdam: John Benjamins Publishing Company.

Crystal, David. 2008. Dictionary of Linguistics and Phonetics. 6th edn. Malden, MA: Blackwell Publishing.

Dink, Jacob W. \& Brock Ferguson. 2015. eyetrackingR: An R Library for Eye-tracking Data Analysis. http://www.eyetrackingr.com.

Dye, Matthew W.G. \& Shui-I Shih. 2006. Phonological priming in British Sign Language. In Lois Goldstein, D.H. Whalen \& Catherine T. Best (eds.), Laboratory Phonology, vol. 
8, 243-263. Berlin, Germany: De Gruyter Mouton.

Emmorey, Karen \& David P. Corina. 1990. Lexical Recognition in Sign Language: Effects of Phonetic Structure and Morphology. Perceptual and Motor Skills 71(3). 1227-1252. doi:10.2466/pms.1990.71.3f.1227.

Emmorey, Karen, Robin L. Thompson \& Rachael Colvin. 2009. Eye Gaze During Comprehension of American Sign Language by Native and Beginning Signers. Journal of Deaf Studies and Deaf Education 14(2). 237-243. doi:10.1093/deafed/enn037.

Grosjean, François. 1980. Sign and Word Recognition: A First Comparison. Sign Language Studies 32. 195-220. doi:10.1353/sls.1982.0003.

Gutiérrez, Eva, Oliver Müller, Cristina Baus \& Manuel Carreiras. 2012. Electrophysiological evidence for phonological priming in Spanish Sign Language lexical access. Neuropsychologia 50(7). 1335-1346. doi:10.1016/j.neuropsychologia.2012.02.018.

Gutiérrez, Eva, Deborah Williams, Michael Grosvald \& David P. Corina. 2012. Lexical access in American Sign Language: An ERP investigation of effects of semantics and phonology. Brain Research 1468. 63-83. doi:10.1016/j.brainres.2012.04.029.

Hanna, Joy E. \& Michael K. Tanenhaus. 2004. Pragmatic effects on reference resolution in a collaborative task: evidence from eye movements. Cognitive Science 28(1). 105-115. doi:10.1207/s15516709 $\operatorname{cog} 2801 \_5$.

Happ, Daniela \& Marc-Oliver Vorköper. 2006. Deutsche Gebärdensprache: Ein Lehr-und Arbeitsbuch. Frankfurt/Main: Fachhochschulverlag.

Hildebrandt, Ursula \& David P. Corina. 2002. Phonological similarity in American Sign Language. Language and Cognitive Processes 17(6). 593-612. doi:10.1080/01690960143000371.

Hillinger, Michael L. 1980. Priming effects with phonemically similar words. Memory \& Cognition 8(2). 115-123. doi:10.3758/bf03213414.

Hosemann, Jana. 2011. Eye gaze and verb agreement in German Sign Language: A first glance. Sign Language \& Linguistics 14(1). 76-93. doi:10.1075/s1l.14.1.05hos.

Hosemann, Jana, Annika Herrmann, Markus Steinbach, Ina Bornkessel-Schlesewsky \& Matthias Schlesewsky. 2013. Lexical prediction via forward models: N400 evidence from German Sign Language. Neuropsychologia 51(11). 2224-2237. doi:10.1016/j.neuropsychologia.2013.07.013.

Hosemann, Jana, Nivedita Mani, Annika Herrmann, Markus Steinbach \& Nicole Altvatermackensen. 2020. Signs activate their written word translation in deaf adults: An ERP study on cross-modal co-activation in German Sign Language. Glossa: a journal of general linguistics 5(1). https://doi.org/10.5334/gjgl.1014.

Just, Marcel A. \& Patricia A. Carpenter. 1980. A theory of reading: From eye fixations to comprehension. Psychological Review 87(4). 329-354. doi:10.1037//0033295x.87.4.329.

Kenstowicz, Michael \& Charles Kisseberth. 1979. Generative phonology: Description and theory. New York, NY: Academic Press.

Klima, Edward S. \& Ursula Bellugi. 1979. The Signs of Language. Cambridge, MA: Harvard University Press. 
Kubus, Okan, Agnes Villwock, Jill P. Morford \& Christian Rathmann. 2015. Word recognition in deaf readers: Cross-language activation of German Sign Language and German. Applied Psycholinguistics 36(4). 831-854. doi:10.1017/S0142716413000520.

Liddell, Scott K. 1984. Think and Belive: Sequentiality in American Sign Language. Language 60(2). 372-399. doi:10.2307/413645.

Liddell, Scott K. \& Robert E. Johnson. 1989. American Sign Language: The phonological base. Sign language studies 64(1). 195-277. doi:10.1353/sls.1989.0027.

Lieberman, Amy M., Arielle Borovsky, Marla Hatrak \& Rachel I. Mayberry. 2015. Real-time Processing of ASL signs: Delayed First Language Acquisition Affects Organization of the Mental Lexicon. Journal of Experimental Psychology: Learning, Memory, and Cognition 41(4). 1130-1139. doi:10.1037/xlm0000088.

Lieberman, Amy M., Arielle Borovsky \& Rachel I. Mayberry. 2017. Prediction in a visual language: real-time sentence processing in American Sign Language across development. Language, Cognition and Neuroscience 1-15. doi:10.1080/23273798.2017.1411961.

Mayberry, Rachel I. \& Pamela Witcher. 2005. What Age of Acquisition Effects Reveal about the Nature of Phonological Processing. Center for Research in Language Technical Reports 17(3). 3-9.

Meade, Gabriela, Brittany Lee, Katherine J. Midgley, Phillip J. Holcomb \& Karen Emmorey. 2018. Phonological and semantic priming in American Sign Language: N300 and N400 effects. Language, Cognition and Neuroscience 33(9). 1092-1106. doi:10.1080/23273798.2018.1446543.

Meade, Gabriela, Katherine J. Midgley, Zed Sevcikova Sehyr, Phillip J. Holcomb \& Karen Emmorey. 2017. Implicit co-activation of American Sign Language in deaf readers: An ERP study. Brain and Language 170. 50-61. doi:10.1016/j.bandl.2017.03.004.

Melinger, A., \& Weber, A. (2006). Database of Noun Associations for German. http://www.psycholing.es.uni-tuebingen.de/nag/index.php

Morford, Jill P., Erin Wilkinson, Agnes Villwock, Pilar Piñar \& Judith F. Kroll. 2011. When deaf signers read English: Do written words activate their sign translations? Cognition 118(2). 286-292. doi:10.1016/j.cognition.2010.11.006.

Morgan, Gary, Sarah Barrett-Jones \& Helen Stoneham. 2007. The first signs of language: Phonological development in British Sign Language. Applied Psycholinguistics 28(01). 3-22. doi:10.1017/S0142716407070014.

Orfanidou, Eleni, Robert Adam, James M. McQueen \& Gary Morgan. 2009. Making sense of nonsense in British Sign Language (BSL): The contribution of different phonological parameters to sign recognition. Memory \& cognition 37(3). 302-315. doi:10.3758/mc.37.3.302.

Ormel, Ellen, Daan Hermans, Harry Knoors \& Ludo Verhoeven. 2012. Cross-language effects in written word recognition: The case of bilingual deaf children. Bilingualism: Language and Cognition 15(2). 288-303. doi: 10.1017/s1366728911000319.

Perniss, Pamela M. 2007. Space and iconicity in German Sign Language (DGS). Nijmegen, Netherlands: Radboud University Doctoral dissertation. 
http://repository.ubn.ru.nl/handle/2066/30937.

Pfau, Roland. 1997. Zur phonologischen Komponente der Deutschen Gebärdensprache:

Segmente und Silben. Frankfurter Linguistische Forschungen 20. 1-29.

Pfau, Roland \& Josep Quer. 2010. Nonmanuals: their grammatical and prosodoc roles. In

Diane Brentari (ed.), Sign Languages (Cambridge Language Sruveys), 381-402.

Cambridge, MA: Cambridge University Press.

Radeau, Monique, José Morais \& Juan Segui. 1995. Phonological priming between monosyllabic spoken words. Journal of Experimental Psychology: Human Perception and Performance 21(6). 1297-1310. doi:10.1037//0096-1523.21.6.1297.

Sandler, Wendy. 1986. The Spreading Hand Autosegment of American Sign Language. Sign Language Studies 50(1). 1-28. doi: 10.1353/sls.1986.0006.

Sandler, Wendy \& Diane Lillo-Martin. 2006. Sign Language and Linguistic Universals. Cambrigde, UK: Cambridge University Press.

Siedlecki Jr, Theodore \& John D. Bonvillian. 1993. Location, Handshape \& Movement: Young Children's Acquisition of the Formational Aspects of American Sign Language. Sign Language Studies 78(1). 31-52. doi:10.1353/sls.1993.0016.

Slowiaczek, Louisa M. \& MaryBeth Hamburger. 1992. Prelexical facilitation and lexical interference in auditory word recognition. Journal of Experimental Psychology: Learning, Memory, and Cognition 18(6). 1239-1250. doi:10.1037//02787393.18.6.1239.

Slowiaczek, Louisa M., James M. McQueen, Emily G. Soltano \& Michelle Lynch. 2000. Phonological representations in prelexical speech processing: Evidence from formbased priming. Journal of Memory and Language 43(3). 530-560. doi:10.1006/jmla.2000.2710.

Slowiaczek, Louisa M. \& David B. Pisoni. 1986. Effects of phonological similarity on priming in auditory lexical decision. Memory \& Cognition 14(3). 230-237. doi:10.3758/bf03197698.

Stokoe, William C. 1960. Sign Language Structure: An Outline of the Visual Communication Systems of the American Deaf (Studies in Linguistics. Occasional Papers 8). Buffalo, NY: University of Buffalo Press.

Stokoe, William C., Dorothy C. Casterline \& Carl G. Croneberg. 1965. A dictionary of American Sign Language on linguistic principles. Washington, D.C.: Gallaudet College Press.

Tanenhaus, Michael K., Michael J. Spivey-Knowlton, Kathleen M. Eberhard \& Julie C. Sedivy. 1995. Integration of visual and linguistic information in spoken language comprehension. Science 268(5217). 1632-1634. doi:10.1126/science.7777863.

Thompson, Robin L., Karen Emmorey \& Tamar H. Gollan. 2005. "Tip of the fingers" Experiences by Deaf Signers. Insights Into the Organization of a Sign-Based Lexicon. Psychological Science 16(11). 856-860. doi:10.1111/j.1467-9280.2005.01626.x.

Thompson, Robin L., Karen Emmorey \& Robert Kluender. 2006. The Relationship between Eye Gaze and Verb Agreement in American Sign Language: An Eye-tracking Study. Natural Language \& Linguistic Theory 24(2). 571-604. doi:10.1007/s11049-0051829-y. 
Thompson, Robin L., David Vinson, Neil Fox \& Gabriella Vigliocco. 2013. Is Lexical Access Driven by Temporal Order or Perceptual Salience? Evidence from British Sign Language. Proceedings of the 35th Annual Meeting of the Cognitive Science Society 35(35). 1450-1455.

Twilhaar, Jan N. \& Beppie van den Bogaerde. 2016. Concise Lexicon for Sign Linguistics. John Benjamins Publishing Company. 


\section{Appendix}

Full list of stimulus material used in the experiment. The sentences are glossed according to DGS word order, but are given in English glosses. Prime and target are boldfaced. In the column describing the differing parameter, the following abbreviations are used: $\mathrm{HS}=$ handshape; $\mathrm{O}=$ orientation; $\mathrm{M}=$ movement; $\mathrm{L}=$ location. For the practice items, some pairs are unrelated so that the parameter column is empty. Items 53 and 54 (marked in grey) were excluded prior to testing. For glosses, small caps are used according to notational conventions. In the stimulus sentences, the following abbreviations are used: IX1 as first person singular pronoun, POSS3 as third person possessive pronoun, CL as classifier and IX as demonstrative.

\begin{tabular}{|c|c|c|c|c|c|c|}
\hline \multirow[t]{2}{*}{$\begin{array}{c}\text { Item } \\
\text { ID }\end{array}$} & \multirow[t]{2}{*}{$\begin{array}{l}\text { Item } \\
\text { name }\end{array}$} & \multirow[t]{2}{*}{$\begin{array}{l}\text { Para- } \\
\text { meter }\end{array}$} & \multicolumn{2}{|c|}{$\begin{array}{c}\text { Minimal pairs } \\
\text { English (German) }\end{array}$} & \multirow[t]{2}{*}{ Distractor picture } & \multirow{2}{*}{$\begin{array}{l}\text { Sentence in priming and unrelated condition } \\
\text { Sentence structure: TIME/PLACE+SUBJ+CL/ADJ/...+OBJ+VERB } \\
\end{array}$} \\
\hline & & & PRIME & TARGET & & \\
\hline $\begin{array}{l}1 \\
2\end{array}$ & $\begin{array}{l}\text { hs01m } \\
\text { hs01o }\end{array}$ & $\begin{array}{l}\text { LOC+ } \\
\text { MOV }\end{array}$ & NOON & WATER & GLASSES & $\begin{array}{l}\text { EVERY-DAY NOON IX1 WATER DRINK SHOULD. } \\
\text { YESTERDAY WORK IX1 WATER FORGET. }\end{array}$ \\
\hline $\begin{array}{l}3 \\
4\end{array}$ & $\begin{array}{l}\text { hs02m } \\
\text { hs02o }\end{array}$ & $\begin{array}{l}\mathrm{LOC}+ \\
\mathrm{MOV}\end{array}$ & ROOM & FAMILY & BUTTERFLY & $\begin{array}{l}\text { NEXT WEEK ROOM IX FAMILY PARTY THERE-IS. } \\
\text { LAST YEAR CHRISTMAS IX FAMILY HAPPY. }\end{array}$ \\
\hline $\begin{array}{l}5 \\
6\end{array}$ & $\begin{array}{l}\text { hs } 03 \mathrm{~m} \\
\text { hs03o }\end{array}$ & $\begin{array}{l}\text { LOC+ } \\
\text { MOV }\end{array}$ & LONDON & TOILETTE & APPLE & $\begin{array}{l}\text { IX1 HOLIDAY LONDON IX TOILET SEARCH. } \\
\text { IX1 CONFERENCE VISIT IX TOILET FIND. }\end{array}$ \\
\hline $\begin{array}{l}7 \\
8\end{array}$ & $\begin{array}{l}\text { hs } 04 \mathrm{~m} \\
\text { hs04o }\end{array}$ & $\begin{array}{l}\text { LOC+ } \\
\text { MOV }\end{array}$ & CAR & ROBOT & FROG & $\begin{array}{l}\text { PARKING PLACE CAR LIKE ROBOT LOOK-LIKE. } \\
\text { COMPANY IX BOSS LIKE ROBOT TALK. }\end{array}$ \\
\hline $\begin{array}{l}9 \\
10\end{array}$ & $\begin{array}{l}\text { hs } 05 \mathrm{~m} \\
\text { hs05o }\end{array}$ & $\begin{array}{l}\text { LOC+ } \\
\text { MOV }\end{array}$ & SPYGLAS & OWL & BRUSH & $\begin{array}{l}\text { YESTERDAY IX1 WITH SPYGLAS IX OWL SEARCH. } \\
\text { LAST WEEK IX1 WITH TELESCOPE IX OWL FIND. }\end{array}$ \\
\hline $\begin{array}{l}11 \\
12\end{array}$ & $\begin{array}{l}\text { hs06m } \\
\text { hs06o }\end{array}$ & $\begin{array}{l}\text { LOC+ } \\
\text { MOV }\end{array}$ & CENTRE & CITY & BOOK & $\begin{array}{l}\text { JUST CENTRE IX CITY VISIT. } \\
\text { YESTERDAY IX1 HOSPITAL IX CITY GO-TO. }\end{array}$ \\
\hline 13 & $\begin{array}{l}\text { hs07m } \\
\text { hs07o }\end{array}$ & $\begin{array}{l}\text { LOC+ } \\
\text { MOV }\end{array}$ & THEATER & CIRCUS & SHIRT & $\begin{array}{l}\text { IN-GENERAL IX THEATER OR CIRCUS LIKE. } \\
\text { BEFORE IX1 CINEMA OR CIRCUS VISIT. }\end{array}$ \\
\hline $\begin{array}{l}15 \\
16\end{array}$ & $\begin{array}{l}\text { hs } 08 \mathrm{~m} \\
\text { hs08o }\end{array}$ & $\begin{array}{l}\mathrm{LOC}+ \\
\mathrm{MOV}\end{array}$ & STRATEGY & HIGHWAY & MUSHROOM & $\begin{array}{l}\text { A-LOT PEOPLE STRATEGY FOR HIGHWAY NEED. } \\
\text { NEW-DRIVER CLEAR RULE FOR HIGHWAY FOLLOW HAVE-TO. }\end{array}$ \\
\hline
\end{tabular}




\begin{tabular}{|c|c|c|c|c|c|c|}
\hline $\begin{array}{l}17 \\
18\end{array}$ & $\begin{array}{l}\text { hs09m } \\
\text { hs09o }\end{array}$ & $\begin{array}{l}\mathrm{LOC}+ \\
\mathrm{MOV}\end{array}$ & CONFERENCE & STADIUM & DOLL & $\begin{array}{l}\text { THIS YEAR CONFERENCE IX STADIUM IS-AT. } \\
\text { LAST MONTH REFERENDUM IX STADIUM TAKE-PLACE. }\end{array}$ \\
\hline $\begin{array}{l}19 \\
20\end{array}$ & $\begin{array}{l}\text { hs } 10 \mathrm{~m} \\
\mathrm{hs} 10 \mathrm{o}\end{array}$ & $\begin{array}{l}\mathrm{LOC}+ \\
\mathrm{MOV}\end{array}$ & DOCTOR & WATCH & BANANA & $\begin{array}{l}\text { FOR WORK DOCTOR IX WATCH HAS. } \\
\text { FOR APPOINTMENTS NURSE IX WATCH WISH. }\end{array}$ \\
\hline $\begin{array}{l}21 \\
22\end{array}$ & $\begin{array}{l}\mathrm{m} 01 \mathrm{~m} \\
\mathrm{~m} 01 \mathrm{o}\end{array}$ & $\begin{array}{l}\mathrm{HS}+ \\
\mathrm{LOC}\end{array}$ & PRESENTATION & TREE & FORK & $\begin{array}{l}\text { YESTERDAY TOPIC PRESENTATION CONTENT TREE CUT-DOWN. } \\
\text { JUST IX1 TV IX REPORT CONTENT TREE SEE. }\end{array}$ \\
\hline $\begin{array}{l}23 \\
24\end{array}$ & $\begin{array}{l}\mathrm{m} 02 \mathrm{~m} \\
\mathrm{~m} 02 \mathrm{o}\end{array}$ & $\begin{array}{l}\mathrm{HS}+ \\
\mathrm{LOC}\end{array}$ & SHOP & ANIMAL & BOTTLE & $\begin{array}{l}\text { USUALLY SHOP IX ANIMALS ENTER ALLOWED-NOT. } \\
\text { OFTEN AT-NIGHT IX ANIMALS SLEEP NEED-NOT. }\end{array}$ \\
\hline $\begin{array}{l}25 \\
26\end{array}$ & $\begin{array}{l}\mathrm{m} 03 \mathrm{~m} \\
\mathrm{~m} 03 \mathrm{o}\end{array}$ & $\begin{array}{l}\mathrm{HS}+ \\
\mathrm{LOC}\end{array}$ & CULTURE & FLOWER & CAP & $\begin{array}{l}\text { INDIA POSS3 CULTURE IX FLOWER IMPORTANT. } \\
\text { WEDDING POSS3 TRADITION IX FLOWER POPULAR. }\end{array}$ \\
\hline $\begin{array}{l}27 \\
28\end{array}$ & $\begin{array}{l}\mathrm{m} 04 \mathrm{~m} \\
\mathrm{~m} 04 \mathrm{o}\end{array}$ & $\begin{array}{l}\mathrm{HS}+ \\
\mathrm{LOC}\end{array}$ & UMBRELLA & COFFEE & BALL & $\begin{array}{l}\text { IX1 BALCONY UMBRELLA UNDER COFFEE DRINK. } \\
\text { IX1 GARDEN ROOF UNDER COFFEE ENJOY. }\end{array}$ \\
\hline $\begin{array}{l}29 \\
30\end{array}$ & $\begin{array}{l}\mathrm{m} 05 \mathrm{~m} \\
\mathrm{~m} 05 \mathrm{o}\end{array}$ & $\begin{array}{l}\mathrm{HS}+ \\
\mathrm{LOC}\end{array}$ & PRACTICE & CAR & TIE & $\begin{array}{l}\text { STUDENT-DRIVER IX A-LOT PRACTICE WITH CAR NEED. } \\
\text { PROFESSIONAL-DRIVER IX A-LOT EXPERIENCE WITH CAR HAS. }\end{array}$ \\
\hline $\begin{array}{l}31 \\
32\end{array}$ & $\begin{array}{l}\mathrm{m} 06 \mathrm{~m} \\
\mathrm{~m} 06 \mathrm{o}\end{array}$ & $\begin{array}{l}\mathrm{HS}+ \\
\mathrm{LOC}\end{array}$ & WORK & UMBRELLA & LETTER & $\begin{array}{l}\text { YESTERDAY IX1 POSS1 WORK IX UMBRELLA FORGET. } \\
\text { OFTEN IX1 POSS1 COLLEGE IX UMBRELLA LEAVE. }\end{array}$ \\
\hline $\begin{array}{l}33 \\
34\end{array}$ & $\begin{array}{l}\mathrm{m} 07 \mathrm{~m} \\
\mathrm{~m} 07 \mathrm{o}\end{array}$ & $\begin{array}{l}\mathrm{HS}+ \\
\mathrm{LOC}\end{array}$ & CITY & LEMON & SQUIRREL & $\begin{array}{l}\text { ITALY CITY IX LEMON BUY CAN. } \\
\text { USUALLY CHILD IX LEMON EAT LIKE-NOT. }\end{array}$ \\
\hline $\begin{array}{l}35 \\
36\end{array}$ & $\begin{array}{l}\mathrm{m} 08 \mathrm{~m} \\
\mathrm{~m} 08 \mathrm{o}\end{array}$ & $\begin{array}{l}\mathrm{HS}+ \\
\mathrm{LOC}\end{array}$ & INTERVIEW & ALLEY & COW & $\begin{array}{l}\text { NEWSPAPER MAYOR INTERVIEW OVER ALLEY PUBLISH. } \\
\text { INTERNET IX REPORTER PHOTO OVER ALLEY UPLOAD. }\end{array}$ \\
\hline $\begin{array}{l}37 \\
38\end{array}$ & $\begin{array}{l}\mathrm{m} 09 \mathrm{~m} \\
\mathrm{~m} 09 \mathrm{o}\end{array}$ & $\begin{array}{l}\mathrm{HS}+ \\
\mathrm{LOC}\end{array}$ & BUS & COCKTAIL & FENCE & $\begin{array}{l}\text { YESTERDAY EVENING POSS1 FRIEND BUS IX COCKTAIL DRINK. } \\
\text { HOLIDAY IX POSS1 FATHER BEACH IX COCKTAIL ENJOY. }\end{array}$ \\
\hline $\begin{array}{l}39 \\
40\end{array}$ & $\begin{array}{l}\mathrm{m} 10 \mathrm{~m} \\
\mathrm{~m} 10 \mathrm{o}\end{array}$ & $\begin{array}{l}\mathrm{HS}+ \\
\mathrm{LOC}\end{array}$ & VILLAGE & ISLAND & RIBBON & $\begin{array}{l}\text { LANDSCAPE GREEN IX VILLAGE LIKE ISLAND NICE LOOK. } \\
\text { PARKING PLACE GREY IX FLOWER LIKE ISLAND APPEAR. }\end{array}$ \\
\hline $\begin{array}{l}41 \\
42\end{array}$ & $\begin{array}{l}101 \mathrm{~m} \\
101 \mathrm{o}\end{array}$ & $\begin{array}{l}\mathrm{HS}+ \\
\mathrm{MOV}\end{array}$ & MINUTE & DOCTOR & $\mathrm{TV}$ & $\begin{array}{l}\text { TWENTY MINUTES IX DOCTOR COME. } \\
\text { EVERY-DAY SECRETARY IX DOCTOR SUPPORT. }\end{array}$ \\
\hline
\end{tabular}




\begin{tabular}{|c|c|c|c|c|c|c|}
\hline $\begin{array}{l}43 \\
44\end{array}$ & $\begin{array}{l}102 \mathrm{~m} \\
102 \mathrm{o}\end{array}$ & $\begin{array}{l}\text { HS+ } \\
\text { MOV }\end{array}$ & PIG & GRANDMA & BOAT & $\begin{array}{l}\text { FARM IX PIG POSS1 GRANDMA ALWAYS BITE. } \\
\text { AT-HOME IX NEIGHBOR POSS1 GRANDMA ALWAYS TEASE. }\end{array}$ \\
\hline $\begin{array}{l}45 \\
46\end{array}$ & $\begin{array}{l}103 \mathrm{~m} \\
103 \mathrm{o}\end{array}$ & $\begin{array}{l}\mathrm{HS}+ \\
\mathrm{MOV}\end{array}$ & REPORTER & JUDGE & CAT & $\begin{array}{l}\text { TOPIC LAW REPORTER IX JUDGE AGAIN ASK. } \\
\text { AT-THE-MOMENT POSS1 FRIEND IX JUDGE WATCH. }\end{array}$ \\
\hline $\begin{array}{l}47 \\
48\end{array}$ & $\begin{array}{l}104 \mathrm{~m} \\
104 \mathrm{o}\end{array}$ & $\begin{array}{l}\mathrm{HS}+ \\
\mathrm{MOV}\end{array}$ & KINDERGARTEN & BIKINI & KEY & $\begin{array}{l}\text { USUALLY KINDERGARTEN IX BIKINI ODD ATTRACT-ATTENTION. } \\
\text { YESTERDAY POSS1 DARLING IX BIKINI NEW BUY. }\end{array}$ \\
\hline $\begin{array}{l}49 \\
50\end{array}$ & $\begin{array}{l}105 \mathrm{~m} \\
105 \mathrm{o}\end{array}$ & $\begin{array}{l}\mathrm{HS}+ \\
\mathrm{MOV}\end{array}$ & MEANING & BIRD & SKIRT & $\begin{array}{l}\text { ZOO CAGE EMPTY MEANING IX BIRD RUN-AWAY. } \\
\text { TREE IX NEST THERE-IS REASON IX BIRD HATCH. }\end{array}$ \\
\hline $\begin{array}{l}51 \\
52\end{array}$ & $\begin{array}{l}106 \mathrm{~m} \\
106 \mathrm{o}\end{array}$ & $\begin{array}{l}\mathrm{HS}+ \\
\mathrm{MOV}\end{array}$ & SUN & SHOWER & BACKPACK & $\begin{array}{l}\text { BEFORE SUN IX1 SHOWER NEED. } \\
\text { AFTER OPERATION IX1 SHOWER USE ALLOWED-NOT. }\end{array}$ \\
\hline $\begin{array}{l}53 \\
54\end{array}$ & $107 \mathrm{~m}$ & $\begin{array}{l}\mathrm{HS}+ \\
\mathrm{MOV}\end{array}$ & KING & PIG & RULER & $\begin{array}{l}\text { CHILDREN-STORIES IX PIG SUDDENLY KING TURN-INTO. } \\
\text { REALITY IX BEGGAR SUDDENLY KIND BARELY HAPPEN. }\end{array}$ \\
\hline $\begin{array}{l}55 \\
56\end{array}$ & $\begin{array}{l}108 \mathrm{~m} \\
108 \mathrm{o}\end{array}$ & $\begin{array}{l}\mathrm{HS}+ \\
\mathrm{MOV}\end{array}$ & PIPE & BUS & CHURCH & $\begin{array}{l}\text { TRAFFIC IX PIPE IX BUS DISRUPT. } \\
\text { STREET IX NEWSPAPER IX BUS DRIVE-OVER. }\end{array}$ \\
\hline $\begin{array}{l}57 \\
58\end{array}$ & $\begin{array}{l}109 \mathrm{~m} \\
109 \mathrm{o}\end{array}$ & $\begin{array}{l}\mathrm{HS}+ \\
\mathrm{MOV}\end{array}$ & FLAG & FISH & TROUSERS & $\begin{array}{l}\text { CHILDREN IX FLAG WITH FISH PAINT. } \\
\text { ART IX A-LOT PICTURE WITH FISH THERE-IS. }\end{array}$ \\
\hline $\begin{array}{l}59 \\
60\end{array}$ & $\begin{array}{l}110 \mathrm{~m} \\
110 \mathrm{o}\end{array}$ & $\begin{array}{l}\text { HS+ } \\
\text { MOV }\end{array}$ & GRANDMA & CLOWN & CHAIR & $\begin{array}{l}\text { CIRCUS PERFORMANCE POSS1 GRANDMA IX CLOWN LIKE-NOT } \\
\text { STORIES IX POSS1 DAUGHTER IX CLOWN LOVE. }\end{array}$ \\
\hline 61 & ueb01 & --- & CHAOS & ORANGE & SCISSORS & OFTEN SUPERMARKET IX1 ORANGE BUY. \\
\hline 62 & ueb02 & $\begin{array}{c}\mathrm{HS}+\mathrm{M} \\
\mathrm{OV}\end{array}$ & HILL & WOMAN & TRASH BIN & YESTERDAY BAVARIA IX HILL IX WOMAN STAND. \\
\hline 63 & ueb03 & $\begin{array}{l}\text { LOC+ } \\
\text { MOV }\end{array}$ & GRAVE & SHIP & NEEDLE & SEA IX CAPTAIN POSS3 GRAVE IF SHIP SINK. \\
\hline 64 & ueb04 & --- & PRAISE & DOG & WATERING CAN & EVERY DAY PARK IX DOG BALL SEARCH. \\
\hline 65 & ueb05 & --- & MOTHER & SHOES & TOMATO & YESTERDAY POSS1 MOTHER IX SHOES NEW BUY. \\
\hline
\end{tabular}


